Canadian Journal of Fisheries and Aquatic Sciences

Canadian Science Publishing Journal canadien des sciences halieutiques et aquatiques

\title{
Heavy sea louse infection is associated with decreased stomach fullness in wild juvenile sockeye salmon
}

\begin{tabular}{|c|c|}
\hline Journal: & Canadian Journal of Fisheries and Aquatic Sciences \\
\hline Manuscript ID & cjfas-2017-0267.R1 \\
\hline Manuscript Type: & Article \\
\hline Date Submitted by the Author: & 29-Nov-2017 \\
\hline Complete List of Authors: & $\begin{array}{l}\text { Godwin, Sean; Simon Fraser University, } \\
\text { Krkošek, Martin; University of Toronto, Department of Ecology and } \\
\text { Evolutionary Biology } \\
\text { Reynolds, John D.; Simon Fraser University, Department of Biological } \\
\text { Sciences } \\
\text { Rogers, Luke; University of Toronto, Department of Ecology and } \\
\text { Evolutionary Biology } \\
\text { Dill, Lawrence; Simon Fraser University, }\end{array}$ \\
\hline $\begin{array}{r}\text { Is the invited manuscript for } \\
\text { consideration in a Special } \\
\text { Issue? : }\end{array}$ & N/A \\
\hline Keyword: & $\begin{array}{l}\text { FORAGING < General, PARASITES < Organisms, SALMON < Organisms, } \\
\text { COMPETITION < General }\end{array}$ \\
\hline
\end{tabular}


1 Heavy sea louse infection is associated with decreased stomach fullness in wild juvenile sockeye 2 salmon

3 Sean C. Godwin ${ }^{1, *}$, Martin Krkošek ${ }^{2,3}$, John D. Reynolds ${ }^{1}$, Luke A. Rogers ${ }^{2}$, Lawrence M. Dill ${ }^{1}$

4

$5 \quad{ }^{1}$ Earth to Ocean Research Group, Department of Biological Sciences, Simon Fraser University,

6 Burnaby, British Columbia, Canada, V5A 1S6

$7 \quad{ }^{2}$ Department of Ecology and Evolutionary Biology, University of Toronto, Toronto, Ontario,

$8 \quad$ Canada, $M 5 S 3 B 2$

$9 \quad{ }^{3}$ Salmon Coast Field Station, Simoom Sound, British Columbia, Canada, VOP 1 SO

10 *Corresponding author: E-mail: sgodwin@sfu.ca, Tel: 778-782-3989

11

12 Co-author e-mail addresses:

13 Martin Krkošek: martin.krkosek@utoronto.ca

14 John Reynolds: reynolds@sfu.ca

$15 \quad$ Luke Rogers: luke.rogers@mail.utoronto.ca

$16 \quad$ Lawrence Dill: ldill@sfu.ca 
17

\section{Abstract}

Foraging success can be mediated by parasites, but this is poorly understood for marine fish whose aggregations and patchy prey fields create conditions for intense intraspecific competition. We evaluated whether sea louse infection is associated with decreased stomach fullness of wild juvenile sockeye salmon (Oncorhynchus nerka) in Johnstone Strait, BC during their marine migration from the Fraser River. Caligus clemensi comprised $98.6 \%$ of the pre-adult and adult lice and $86.5 \%$ of the copepodites (freshly attached juvenile lice); the rest were Lepeophtheirus salmonis. We found that infection status was an important predictor of relative stomach fullness for juvenile sockeye (wet stomach content weight divided by body weight), as indicated by mixed-effects model selection, and that highly infected fish had $17 \% \pm$ $8 \%$ lower relative stomach fullness than did lightly infected fish. This louse-associated reduction in relative stomach fullness occurs as the juvenile sockeye migrate through a food-limited environment, and presumably elevated competition. Given that early marine growth for juvenile salmon is often a predictor of survival, our results highlight the importance of understanding sublethal effects of parasites on salmonids and possibly other fish species. 


\section{Introduction}

Foraging success is tightly linked to growth and survival of individuals, both of which are predictors of fitness and population dynamics (Crombie 1947; Sutherland 1996). Fish frequently experience patchy foraging opportunities and aggregate in large groups that intensify competition (see review by Ward et al. (2006)), and consequently survival often depends on these competitive outcomes (e.g., Resetarits 1995; Welker et al. 1994). This is especially the case for juvenile fishes, whose early growth depends on food supply and often determines survival and recruitment (Anderson 1988; Bergenius et al. 2002; Houde and Hoyt 1987). Evidence suggests that parasites affect competitive foraging outcomes of hosts, thereby influencing host population dynamics, community structure, and biodiversity (see Hatcher et al. 2006). However, this evidence is primarily from terrestrial species (e.g., Grosholz 1992; Maksimowich and Mathis 2000; Schall 1992). Despite what is likely a more competitive environment with food patchiness and consumer aggregation for fishes, there is little work in the fisheries literature on how parasites mediate competition in wild fish and whether this translates to decreased survival through reduced foraging success and growth (but see Finley and Forrester 2003).

Pacific salmon (Oncorhynchus spp.), like many fishes, experience high juvenile mortality from predation and starvation (Groot and Margolis 1991; Parker 1968). Consequently, the impacts of parasitism may be primarily expressed through the mechanisms by which parasitism affects inter- and intra- specific interactions. Juvenile Pacific salmon migrate in large groups to swamp and evade predators (Eggers 1978; Furey et al. 2016), so competition for food is probable in regions with low prey availability (McKinnell et al. 2014). Foraging success during the marine migration of juvenile salmon likely affects growth, which is often a predictor of survival (Duffy and Beauchamp 2011; Farley et al. 2007; Moss et al. 2005), so competition in environments of 
low foraging opportunity is one plausible mechanism through which parasites may affect survival of juvenile salmon (Godwin et al. 2015). Although parasitism can raise energetic requirements and thereby increase foraging rate (e.g., Giles 1987; Shi et al. 2002), parasitism may also interfere with the behavioural process of obtaining food in a food-limited environment and thereby reduce foraging success (e.g., Barber and Ruxton 1998).

During the ocean phase of their juvenile migration, Pacific salmon are susceptible to infection by sea lice (Lepeophtheirus salmonis and Caligus clemensi), which are native ectoparasites that feed on the surface tissue of their host (Wootten et al. 1982). Juvenile Pacific salmon normally have low infection levels of sea lice, especially the salmonid specialist $L$. salmonis, because these salmon are temporally and spatially separated from adult Pacific salmon (Krkošek et al. 2007). However, in recent decades domesticated Atlantic salmon (Salmo salar) farmed in open-net pens in coastal British Columbia $(\mathrm{BC})$ have provided year-round reservoirs for sea lice that allow substantial transmission of L. salmonis to juvenile Pacific salmon (Costello 2009b; Groner et al. 2016). For the generalist $C$. clemensi, there also exist other natural host infection reservoirs, such as Pacific herring (Clupea pallasii) (Beamish et al. 2009; Morton et al. 2008), which share nearshore coastal waters with juvenile salmon as spawners and larvae (Beamish et al. 2012).

In recent years, the generalist $C$. clemensi has infected over $98 \%$ of out-migrating juvenile sockeye salmon (O. nerka) from the Fraser River (Godwin et al. 2015; Godwin et al. 2017), an iconic set of Pacific salmon populations that forms Canada's largest sockeye run. Juvenile sockeye salmon that experience high infection intensity by $C$. clemensi exhibit reduced foraging success in a competitive and food-limited experimental setting (Godwin et al. 2015). Whether this translates to reduced foraging success in the wild is still unknown, but is the focus 
of this work. Here, we tested whether the relative stomach fullness (wet stomach content weight divided by body weight) of wild juvenile sockeye is lower when sea louse infection intensity is higher, which has implications for our understanding of how parasites mediate competition in fishes and potentially for the management of $C$. clemensi in BC.

\section{Methods}

Fish collection

We collected juvenile sockeye salmon in the wild as they migrated through western Johnstone Strait, BC, between May 26 and June 7, 2014 (Fig. 1). At this point in their migration, the sockeye post-smolts have well-developed scales and average $114 \mathrm{~mm}$ in fork length. We used a hand-operated purse seine net (bunt: $27 \times 9 \mathrm{~m}$ with $13 \mathrm{~mm}$ mesh, tow: $46 \times 9 \mathrm{~m}$ with 76 $\mathrm{mm}$ mesh) that we set from a small $(6 \mathrm{~m})$ open boat. After surrounding the fish, we brought the net next to the boat to form a pocket of sufficient width and depth to allow the fish to swim freely and minimize their contact with the mesh.

We transferred captured fish from the net into an insulated fish tote $(0.58 \mathrm{~m}$ deep and $0.97 \times 0.55 \mathrm{~m}$ across) filled with fresh seawater. We moved fish from the net into the tote by dipping them and their surrounding seawater into a 3.79 L container (an inverted milk jug with the top capped and bottom cut off). This transfer method minimized or prevented sea louse detachment as fish were never exposed to air and there was minimal contact between the fish and sampling equipment (Godwin et al. 2015). All subsequent transfers were also performed using the same method. We used ice packs to regulate water temperature in the tote and aquarium bubblers to maintain adequate aeration. We transferred 50-100 sockeye into the tote during each capture event. See Supplementary Table S1 for collection locations, catch sizes, and 
oceanographic data.

102

103

104

105

106

107

108

109

110

111

112

113

114

115

116

117

118

119

120

121

122

123

\section{Infection status assessment}

We transferred sockeye individually from the tote into $13.2 \mathrm{~L}$ clear plastic aquaria and assessed them for sea louse infection by eye. If a fish appeared to be in one of our two infection categories (see below), we recorded that category and transferred the fish to an individual sterile $532 \mathrm{~mL}$ sample bag (Whirl-Pak ${ }^{\circledR}$ Write-On Bags; Nasco, Fort Atkinson, Wisconsin, USA) and euthanized it with an overdose of MS-222 $\left(240 \mathrm{mg} \mathrm{L}^{-1}\right)$. After euthanizing a fish, we performed a full assessment of its infection status using a hand lens (Krkošek et al. 2005a) to confirm its infection category. Fish that were euthanized but found not to meet our infection category criteria were not used; such fish accounted for approximately $10 \%$ of euthanized fish and were usually identified initially to be in the lightly infected category by eye but then found to have too many small juvenile lice upon inspection by hand lens. We alternated between processing highly infected and lightly infected fish so as to not confound digestion time with infection status.

Larger, more developed sea lice have greater effects on their hosts (Jakob et al. 2013; Nendick et al. 2011; Wootten et al. 1982). We created infection categories that reflected this differential level of pathogenicity, so that small juvenile lice were not weighted equally to large adult lice (similar to Peacock et al. 2015). Sea lice initially attach to their host as copepodites, then develop through two (L. salmonis; Hamre et al. 2013) or four (C. clemensi; Kabata 1972) attached chalimus stages of increasing size before molting into their motile pre-adult and adult stages. Here, we consider individuals in their second L. salmonis chalimus stage or their third or fourth C. clemensi chalimus stages as 'large chalimus' sea lice; we also consider pre-adult and adult individuals as 'motile' sea lice. To weight the infection statuses of fish according to the 
124 development of lice infecting them, we defined a louse infection scale in which one large

125 chalimus louse was equal to one infection unit, one motile louse was equal to two infection units,

126 and copepodite and small chalimus lice were equal to zero. Because of the high infection

127 prevalence observed ( $>98 \%$ ), we were unable to create a category for uninfected fish. Instead,

128 we created a 'lightly infected' category in which all the fish had zero infection units and no more

129 than three copepodite or small chalimus lice (Table 1). In all collections, the 'lightly infected'

130 and 'highly infected' categories differed by a minimum of three infection units. See

131 Supplementary Table S2 for the detailed sea louse infection data.

132 Approximately one hour after capture, we released the remaining fish at the collection

133 site. In each collection, we retained five to seven pairs of fish, each consisting of a lightly and

134 highly infected sockeye. In total, we retained 130 juvenile sockeye salmon from across 11

135 collections to analyze stomach fullness in relation to infection status.

$137 \quad$ Zooplankton sampling and analysis

138 Immediately following the infection status assessments and subsequent release of fish, we 139 collected zooplankton samples with a horizontal plankton tow at the fish capture site. Plankton 140 tows were performed with a $0.5 \mathrm{~m}$ diameter plankton net with $250 \mu \mathrm{m}$ mesh. The top of the net 141 was kept $5-10 \mathrm{~cm}$ below the ocean surface, on average, and the tow lasted for $30 \mathrm{~s}$. We attached 142 a calibrated flow meter (General Oceanics, Miami, Florida, USA) at the mouth of the net to 143 measure the volume of water sampled. We used horizontal tows instead of vertical ones because 144 plankton samples near the surface are more similar to sockeye diets than those from deeper in the 145 water column (Landingham et al. 1998) and our field observations indicate that juvenile sockeye 146 frequently occupy the surface waters at the collection sites. 
Each plankton sample was placed in a glass jar containing $250 \mathrm{~mL}$ of $10 \%$ formalinseawater solution. Within three days of the collection, the samples were poured into a $63 \mu \mathrm{m}$ sieve and rinsed with distilled water. The samples were then halved repeatedly using a Folsom plankton splitter (Aquatic Research Instruments, Hope, Idaho, USA) until approximately 200250 individuals remained, after which they were transferred to a Bogorov counting tray (Wildlife Supply Company, Yulee, Florida, USA). From these samples, we identified and enumerated individuals from the high-level taxa previously found in juvenile Fraser River sockeye salmon stomachs (Price et al. 2013); these were termed 'sockeye prey'. These high-level taxa from Price et al. (2013) were: Copepoda, Brachyura, Oikopleura, Euphausiacea, Cladocera, Pteropoda, Decapoda, Amphipoda, Insecta, Cumacea, fish, and eggs. We calculated sockeye prey density by multiplying the number of sockeye prey in the Bogorov tray by the reciprocal of the splitting fraction, then dividing by the volume of water that passed through the plankton net.

\section{Determination of relative stomach fullness}

We used wet stomach content weight as our measure of stomach fullness, and divided this by the fish's body weight to calculate relative stomach fullness. Following the field collections, we transported the euthanized fish on ice to a laboratory facility 45 min away by boat. Upon arrival at the laboratory, fish were analyzed in the original order of collection by dissecting them immediately to weigh the wet stomach contents. Stomachs were excised between the lower oesophagus and the pyloric sphincter, and their contents extruded with forceps and weighed, as in Godwin et al. (2015).

\section{Statistical analysis}


To determine which biological variables best explained juvenile sockeye salmon relative

171

172

173

174

175

176

177

178

179

180

181

182

183

184

185

186

187

188

189

190

191

192 stomach fullness, we fit a suite of 13 mixed-effects models to our data (see Supplementary Table S3 for the full model set). Our models included the biologically relevant combinations of five fixed effects: infection status, body size, prey density, the two-way interaction between infection status and body size, and the two-way interaction between infection status and prey density. We included infection status as a fixed effect to test our main hypothesis that relative stomach fullness decreases with high intensities of sea louse infection. We included body size and its interaction with infection status to account for any additional benefit of a larger body size to relative stomach fullness, and the potential decreasing effect of infection with body size (Godwin et al. 2015). Finally, we included prey density and its interaction with infection status to account for the probable association between relative stomach fullness and prey density, and the possible decreasing effect of infection with increasing density of prey. Prey density and relative stomach fullness were centered and scaled by one standard deviation to allow the model-fitting optimizer to function correctly, since their variances were different by 10 orders of magnitude. Each model included a random effect of collection number on the intercept, which was determined a priori to account for the hierarchical structure of the sampling design, and a variance structure allowing for different variances in each collection to account for heteroscedasticity in the residuals. We performed model selection using Akaike Information Criterion corrected for small sample sizes (Hurvich and Tsai 1989) as our measure of model parsimony. We calculated relative variable importance (RVI) values based on the AICc weights.

We derived our measure of body size from a principal component analysis using three highly correlated body metrics: fork length, body depth, and weight. The first principal component explained $98 \%$ of the original variation in these metrics and so we used that as the 
193

194

195

196

197

198

199

200

201

202

203

204

205

206

207

208

209

210

211

212

213

214

215

variable representing body size in the statistical analyses.

We tested for differences in body size between infection categories using a two-sample $t$ test, and used linear regression to assess whether motile or overall louse abundance increased with body size for the highly infected fish. We completed all our analysis in R 3.2.1 (R Foundation for Statistical Computing, 2015) using the nlme and MuMIn packages.

\section{Results}

The juvenile sockeye salmon in our highly infected category were primarily infected by C. clemensi rather than L. salmonis, with $98.6 \%$ of the motile sea lice and $86.5 \%$ of the copepodid lice infecting these fish belonging to the former species. Neither motile abundance $\left(R^{2}\right.$ $=0.009$, d.f. $=63, p=0.455)$ nor overall louse abundance $\left(R^{2}=0.025\right.$, d.f. $\left.=63, p=0.207\right)$ increased with body size for fish in the highly infected category. Body size also did not differ between infection categories $(t=0.282$, d.f. $=128, p=0.779)$. The mean $( \pm \mathrm{SE})$ zooplankton density across all collections was 941 individuals $\mathrm{L}^{-1} \pm 141$ individuals $\mathrm{L}^{-1}$, and the mean sockeye prey density was 772 individuals $\mathrm{L}^{-1} \pm 134$ individuals $\mathrm{L}^{-1}$, indicating that potential sockeye prey constituted $82 \%$ of the zooplankton community in the surface waters during our collections.

Lightly infected fish had higher relative stomach fullness than highly infected fish (Fig. 2), and this trend held in each of the 11 collections (Fig. 3). Infection status was the most important predictor of relative stomach fullness; of the 13 mixed-effects models, the top nine all included an infection status term, while none of the bottom four did (Supplementary Table S3). The importance of infection status to relative stomach fullness was corroborated by this predictor having the highest RVI (0.97), compared with body size (0.66), prey density (0.60), the 
216 interaction between infection status and prey density (0.16), and the interaction between

217 infection status and body size (0.14). Regardless of their rank, all models with the relevant terms

218 revealed that relative stomach fullness was higher for lightly infected fish, that it increased with

219 body size, and that it increased with prey density. The top-ranked model included only an

220 infection status term, but two other models were within 2 AICc units of the top model and

221 therefore also had substantial support (Burnham and Anderson 2002; Table 2). One of these

222 highly-supported models included a body size term, while the other included a predictor for prey 223 density (Table 2).

224 The highest-ranked model without an infection status predictor was 7.8 AICc units higher 225 than the top model and accounted for only $0.7 \%$ of model support, as judged by AICc weights 226 (Supplementary Table S2). The top-ranked model was 51 times more likely than the highest227 ranked model without an infection status predictor, and its coefficients indicated that highly 228 infected fish had $17 \% \pm 8 \%$ lower relative stomach fullness than lightly infected fish, on 229 average.

\section{Discussion}

Theory and empirical evidence suggest that pathogens and parasites can influence host 233 survival and population dynamics by modulating competitive foraging interactions (Hatcher et 234 al. 2006). However, there is little evidence of parasite-mediated intraspecific competition in wild 235 fishes, for whom intraspecific competition may be particularly intense due to fish aggregation 236 and food patchiness. Our results indicate that, for wild juvenile sockeye salmon, high levels of 237 sea louse infection are associated with reduced relative stomach fullness. The juvenile sockeye 238 used in this study were captured during their early marine migration from their natal freshwater 
239 systems, which based on the timing of capture and genetic analyses from previous studies

240 (Godwin et al. 2017; Groot and Cooke 1987; Price et al. 2011) were mostly in the Fraser River 241 watershed of BC.

242 While our stomach fullness data describe the quantity of prey consumed by sockeye, it 243 should be noted that stomach fullness is not a true measure of foraging success or efficiency. 244 Stomach fullness does not account for the energy densities or digestibility of prey, which vary 245 among the zooplankton prey items that dominate the diet of juvenile sockeye (Foy and Norcross 246 1999; Lee 1974) as well as spatially and temporally with the availability of those items 247 (Landingham et al. 1998; Mackas et al. 2013; Tanasichuk and Routledge 2011). Parasitized 248 individuals can shift their diet to prey items of lower energy density or digestibility when they 249 struggle to compete with unparasitized conspecifics for higher-quality prey (Milinski 1984). 250 Since juvenile sockeye with heavy sea louse infection have lower competitive foraging abilities 251 (Godwin et al. 2015), it is possible that they too shift toward capturing more prey items of lower 252 quality. If that were the case, then by using stomach fullness data we produced conservative 253 estimates of the differences in foraging success between infection categories.

254 Animal migration is generally demanding metabolically, so managing energy gain and 255 depletion is vital for most migrating animals to avoid starvation or the sub-lethal effects of 256 depleted energy reserves (Sapir et al. 2011). Unlike some migratory species, juvenile sockeye 257 salmon forage during their migration, but this foraging is temporally variable because feeding 258 opportunities are patchy (McKinnell et al. 2014; Parsons et al. 1970). In regions with relatively 259 high productivity, such as the northern Strait of Georgia, BC (Masson and Peña 2009; Parsons et 260 al. 1970), no evidence of food limitation has been observed (Price et al. 2013). By contrast, the 261 region in which we captured fish for this study, Johnstone Strait, has a sparse prey field due to 
262

263

264

265

266

267

268

269

270

271

strong tidal mixing (B. Hunt et al., Hakai Institute, unpublished data), which may cause high mortality for juvenile sockeye that enter the Strait with insufficient energy reserves (McKinnell et al. 2014). Sea lice levels on juvenile sockeye are also considerably higher in Johnstone Strait than in the more productive southern regions (Godwin et al. 2015; Price et al. 2011). Hence, the potential effects of sea lice on sockeye salmon growth and survival in Johnstone Strait are likely to involve the elevated abundances of the parasite itself, its effects on intraspecific competition, and the intensification of competition due to food limitation and the energy expenditure of migration.

Our results provide equivocal evidence for an association between prey density and the relative stomach fullness of juvenile sockeye. If food competition is indeed higher in Johnstone Strait for sockeye than in nearby regions and that contributed to our finding that relative stomach fullness is associated with heavy sea louse infection, then we might have expected to find a stronger relationship between prey density and relative stomach fullness. Only one our three models with considerable support (as judged by AICc values; Burnham and Anderson 2002) contained a prey density predictor, which across our model set was our third most important predictor variable $(\mathrm{RVI}=0.60)$. It is possible that prey density did not severely limit relative stomach fullness of sockeye in Johnstone Strait in 2014 even if food availability is commonly much lower there than in the Strait of Georgia (McKinnell et al. 2014; B. Hunt et al., Hakai Institute, unpublished data.). However, if the prey field was not limiting sockeye foraging rates then we might not expect to observe the differences in relative stomach fullness between infection categories that we did, since highly infected (and therefore less competitive (Godwin et al. 2015)) individuals would still have the opportunity to feed to satiation. It is also possible that the prey density estimates from our zooplankton collections did not represent the prey field 
encountered by the fish when they were feeding, due to patchiness in time or space (Parsons et al. 1970) or the strong tidal currents known to occur in Johnstone Strait (Sutherland et al. 2007). Most of the sockeye in this study must have eaten in the preceding eight hours (see Appendix), which limits the potential effects of patchiness and currents on our results, but these remain possibilities that cannot be excluded. Perhaps the most likely explanation for our equivocal evidence of a relationship between prey density and relative stomach fullness was that the sample size of 11 collection sites was too small to detect an effect. While our study design was suitable for looking at consistent differences in relative stomach fullness within groups, the sample size was limited for investigating variation among collections. is correlative, but the weight of evidence is building that sea lice have sub-lethal effects on important determinants of sockeye salmon survival. Sea lice are associated with Pacific salmon population declines (Connors et al. 2010; Krkošek et al. 2011a), but these declines cannot be explained by direct mortality alone, which may only be significant at small host sizes (Jones et al. 2008). However, sea lice also appear to have sub-lethal effects that influence mortality through their hosts' ecological interactions, for example by reducing swimming endurance (Mages and Dill 2010), increasing risk-taking behaviours (Krkošek et al. 2011b), and elevating predation (Peacock et al. 2015). For juvenile sockeye salmon specifically, individuals that are heavily infected by sea lice, primarily C. clemensi, have lower competitive foraging ability (Godwin et al. 2015), reduced body growth (Godwin et al. 2017), and actively attempt to dislodge these parasites by leaping (Atkinson et al. In review). Nonetheless, laboratory studies utilizing experimental infections are needed to help differentiate two alternative interpretations of our results: 1) that sea lice abundance is a consequence rather than a cause of variation in 
relative stomach fullness; or 2) that sea louse abundance and relative stomach fullness are both correlated with (signals of) fundamental underlying fitness variation among individuals. We consider these alternative explanations to be unlikely because they both require sustained differences in relative stomach fullness that would have led to a difference in body size between the two infection categories, which was not observed. It is also striking that the observed louseassociated differences in relative stomach fullness occurred in each of the 11 collections (Fig 3), so any correlation between an underlying condition and sea louse infection would have to be very strong indeed.

In addition to our main result that heavy sea louse infection is associated with reduced sockeye stomach fullness, we also found moderate evidence that relative stomach fullness increased with body size. This result runs counter to the negative exponential relationship between relative stomach fullness and body size reported by Brett (1971) for juvenile sockeye, 320 suggesting that larger juvenile sockeye may have a foraging advantage due to their body size. 321 The obvious potential mechanism for this is that smaller sockeye are prevented from foraging on 322 larger (and possibly more abundant) prey due to gape limitation, which often, but not always, 323 determines foraging success in young fish (Bremigan and Stein 1994; Devries et al. 1998;

324 Hargreaves and LeBrasseur 1986; Scharf et al. 2000). Together with the relationship between 325 infection status and relative stomach fullness, this potential effect of body size would be consistent with our previous findings that high infection intensities and smaller body sizes are associated with lower competitive foraging ability (Godwin et al. 2015) and reduced growth

(Godwin et al. 2017) for juvenile sockeye. When considered together (Fig. 4), these interconnected relationships suggest that sea louse infection may not just be accompanied by a single, temporary effect for the duration of infection. Infection may instead have long-lasting 
331 effects by initiating and/or intensifying divergent growth among individuals through differences

332 in foraging success, which would create and reinforce intraspecific heterogeneity in body sizes

333 and ultimately differential survival. To detect such differences in body size, the amount of time

334 between sea louse exposure and fish collection would need to be greater than that of this study

335 (3-10 days; Price et al. 2011; Welch et al. 2011), since the small amount of differential body

336 growth that would occur between infection categories in that time $(<0.5 \mathrm{~mm}$; Godwin et al.

337 2017) would be statistically swamped by the individual-level variation in body size. This

338 potential for lasting effects of sea lice on factors critical to sockeye survival highlights the need

339 to consider the anthropogenic influence on the parasite burdens of these fish, and potentially

340 reduce it through management actions when possible.

341 Over $98 \%$ of the motile sea lice infecting the juvenile sockeye salmon were C. clemensi,

342 but although these infections have been linked to open net-pen salmon farms (Price et al. 2011),

343 there are currently no management actions directed at regulating this louse species on farms in

344 BC. Lepeophtheirus salmonis, the main species of sea louse that causes fish mortality and

345 financial loss to salmon aquaculture in the northern hemisphere (Costello 2009a; Johnson et al.

346 2004; Mustafa et al. 2001), is controlled on BC farms through application of in-feed parasiticide

347 (emamectin benzoate; Saksida et al. 2010) when their abundance exceeds three motile lice per

348 fish (Fisheries and Oceans Canada 2016). While emamectin benzoate also reduces C. clemensi

349 numbers, C. clemensi abundance is not directly managed. Since Caligus spp. are considered less

350 pathogenic than L. salmonis (Igboeli et al. 2014; Johnson et al. 2004) and most of the research

351 into the effects of sea lice on wild salmon has focussed on L. salmonis (e.g., Connors et al. 2010;

352 Johnson et al. 1996; Krkošek et al. 2005b), there has been little reason to target C. clemensi with

353 treatments on farms until now. However, given the mounting evidence for sub-lethal effects of 
354 C. clemensi on wild salmon, and the ability for C. clemensi to reach extreme abundances on 355 farms without targeted treatment (e.g., 100\% prevalence and 47.2 lice per fish (Di Cicco et al. 356 2017)), it seems prudent to start considering C. clemensi in the fish health management plans of 357 farmed salmon in BC.

358 There is increasing concern over the potential impacts of C. clemensi on wild Fraser 359 River sockeye salmon (e.g., Moore et al. 2017), especially in the context of the record-low Fraser 360 sockeye returns in 2009 and 2016 (Pacific Salmon Commission 2016). Unlike L. salmonis, 361 which can only infect salmonids, the generalist C. clemensi may have multiple sea lice reservoirs 362 along the juvenile sockeye migration route, including Pacific herring, which may amplify 363 extinction risk for salmon by allowing parasite abundances to remain high when an imperilled 364 host population declines (De Castro and Bolker 2005) and perhaps threaten herring stocks as 365 well. Our results shed further light on the sometimes subtle interactions between parasites and 366 wild Pacific salmon (Miller et al. 2014; Peacock et al. 2014), and underscore the need to study 367 not only the direct mortality from parasites but their sub-lethal effects as well. The impacts of 368 parasite-mediated intraspecific competition on host survival and recruitment may be particularly 369 influential for fishes, which often experience intense food competition and growth-dependent 370 mortality, but there has been little to no work in this area. Competition is a fundamental driver of 371 populations, and identifying how and when parasites mediate the competitive interactions of 372 their hosts may be essential to understanding the host-parasite dynamics of many systems. 


\section{Acknowledgements}

We are grateful to Salmon Coast Field Station and its staff for making this research

375 possible. We thank M. Bartlett, L. Walker, and C. White for their diligent work in the laboratory 376 and field. This work was supported by Simon Fraser University, the University of Toronto, 377 Watershed Watch Salmon Society, V. and D. Bradshaw, a Natural Sciences and Engineering 378 Research Council of Canada (NSERC) Industrial Postgraduate Scholarship (to S. Godwin), an 379 NSERC Alexander Graham Bell Canada Graduate Scholarship (to S. Godwin), NSERC 380 Discovery Grants (to L. Dill, M. Krkošek, and J. Reynolds), an Alfred P. Sloan Foundation 381 Fellowship in Ocean Science and Canada Research Chair (to M. Krkošek), and the Tom Buell 382 Endowment Fund supported by the Pacific Salmon Foundation and the BC Leading Edge 383 Endowment Fund (to J. Reynolds). We performed all fish collection and euthanasia under 384 permits and approval by Fisheries and Oceans Canada (license number XR472014) and the 385 Simon Fraser University Animal Care Committee (protocol number 1088-B13). 


\section{References}

Anderson, J.T. 1988. A review of size dependent survival during pre-recruit stages of fishes in relation to recruitment. Journal of Northwest Atlantic Fishery Science, 8: 55-66.

Atkinson, E., Bateman, A.W., Dill, L.M., Krkošek, M., Reynolds, J.D., and Godwin, S.C. In review. Oust the louse: leaping behaviour removes sea lice from wild juvenile sockeye salmon.

Barber, I., and Ruxton, G.D. 1998. Temporal prey distribution affects the competitive ability of parasitized sticklebacks. Animal Behaviour, 56(6): 1477-1483.

Beamish, R., Wade, J., Pennell, W., Gordon, E., Jones, S., Neville, C., Lange, K., and Sweeting, R. 2009. A large, natural infection of sea lice on juvenile Pacific salmon in the Gulf Islands area of British Columbia, Canada. Aquaculture, 297(1): 31-37. doi: 10.1016/j.aquaculture.2009.09.001.

Beamish, R., Neville, C., Sweeting, R., and Lange, K. 2012. The synchronous failure of juvenile Pacific salmon and herring production in the Strait of Georgia in 2007 and the poor return of sockeye salmon to the Fraser River in 2009. Marine and Coastal Fisheries, 4(1): 403-414.

Bergenius, M.A., Meekan, M.G., Robertson, R.D., and McCormick, M.I. 2002. Larval growth predicts the recruitment success of a coral reef fish. Oecologia, 131(4): 521-525.

Bremigan, M.T., and Stein, R.A. 1994. Gape-dependent larval foraging and zooplankton size: implications for fish recruitment across systems. Canadian Journal of Fisheries and Aquatic Sciences, 51(4): 913-922.

Brett, J. 1971. Satiation time, appetite, and maximum food intake of sockeye salmon (Oncorhynchus nerka). Journal of the Fisheries Board of Canada, 28(3): 409-415. 
Burnham, K.P., and Anderson, D.R. 2002. Model selection and multimodel inference: a practical information-theoretic approach. Springer, New York.

Connors, B.M., Krkošek, M., Ford, J., and Dill, L.M. 2010. Coho salmon productivity in relation to salmon lice from infected prey and salmon farms. Journal of Applied Ecology, 47(6): 1372-1377. doi: 10.1111/j.1365-2664.2010.01889.x.

Costello, M.J. 2009a. The global economic cost of sea lice to the salmonid farming industry. Journal of Fish Diseases, 32(1): 115-118. doi: 10.1111/j.1365-2761.2008.01011.x.

Costello, M.J. 2009b. How sea lice from salmon farms may cause wild salmonid declines in Europe and North America and be a threat to fishes elsewhere. Proceedings of the Royal Society of London B: Biological Sciences, 276(1672): 3385-3394.

Crombie, A.C. 1947. Interspecific competition. The Journal of Animal Ecology, 16(1): 44-73. doi: $10.2307 / 1506$.

De Castro, F., and Bolker, B. 2005. Mechanisms of disease-induced extinction. Ecology Letters, 8(1): 117-126. doi: 10.1111/j.1461-0248.2004.00693.x.

Devries, D.R., Stein, R.A., and Bremigan, M.T. 1998. Prey selection by larval fishes as influenced by available zooplankton and gape limitation. Transactions of the American Fisheries Society, 127(6): 1040-1050.

Di Cicco, E., Ferguson, H.W., Schulze, A.D., Kaukinen, K.H., Li, S., Vanderstichel, R., Wessel, Ø., Rimstad, E., Gardner, I.A., and Hammell, K.L. 2017. Heart and skeletal muscle inflammation (HSMI) disease diagnosed on a British Columbia salmon farm through a longitudinal farm study. PLoS One, 12(2): e0171471. doi: 10.1371/journal.pone.0171471. Duffy, E.J., and Beauchamp, D.A. 2011. Rapid growth in the early marine period improves the marine survival of Chinook salmon (Oncorhynchus tshawytscha) in Puget Sound, 
Washington. Canadian Journal of Fisheries and Aquatic Sciences, 68(2): 232-240. doi: 10.1139/F10-144.

Eggers, D.M. 1978. Limnetic feeding behavior of juvenile sockeye salmon in Lake Washington and predator avoidance. Limnology and Oceanography, 23(6): 1114-1125. doi: 10.4319/1o.1978.23.6.1114.

Farley, E.V., Murphy, J.M., Adkison, M.D., Eisner, L.B., Helle, J.H., Moss, J.H., and Nielsen, J. 2007. Early marine growth in relation to marine-stage survival rates for Alaska sockeye salmon (Oncorhynchus nerka). Fishery Bulletin, 105(1): 121-130.

Finley, R.J., and Forrester, G.E. 2003. Impact of ectoparasites on the demography of a small reef fish. Marine Ecological Progress Series, 248: 305-309.

Fisheries and Oceans Canada. (2016). Marine Finfish Aquaculture Licence under the Fisheries Act. Available from http://www.pac.dfo-mpo.gc.ca/aquaculture/licence-permis/docs/licencecond-permis-mar/licence-cond-permis-mar-eng.pdf. Accessed 2017-04-26.

Foy, R.J., and Norcross, B.L. 1999. Spatial and temporal variability in the diet of juvenile Pacific herring (Clupea pallasi) in Prince William Sound, Alaska. Canadian Journal of Zoology, 77(5): 697-706.

Furey, N.B., Hinch, S.G., Bass, A.L., Middleton, C.T., Minke-Martin, V., and Lotto, A.G. 2016. Predator swamping reduces predation risk during nocturnal migration of juvenile salmon in a high-mortality landscape. Journal of Animal Ecology, 85(4): 948-959. doi: 10.1111/13652656.12528.

Giles, N. 1987. Predation risk and reduced foraging activity in fish: experiments with parasitized and non-parasitized three-spined sticklebacks, Gasterosteus aculeatus L. Journal of Fish Biology, 31(1): 37-44. 
Godwin, S.C., Dill, L.M., Reynolds, J.D., and Krkošek, M. 2015. Sea lice, sockeye salmon, and foraging competition: lousy fish are lousy competitors. Canadian Journal of Fisheries and Aquatic Sciences, 72(7): 1113-1120. doi: 10.1139/cjfas-2014-0284.

Godwin, S.C., Dill, L.M., Krkošek, M., Price, M.H.H., and Reynolds, J.D. 2017. Reduced growth in wild juvenile sockeye salmon infected with sea lice. Journal of Fish Biology, 91(1): 41-57. doi: 10.1111/jfb.13325.

Groner, M.L., Rogers, L.A., Bateman, A.W., Connors, B.M., Frazer, L.N., Godwin, S.C., Krkošek, M., Lewis, M.A., Peacock, S.J., and Rees, E.E. 2016. Lessons from sea louse and salmon epidemiology. Philosophical Transactions of the Royal Society B: Biological Sciences, 371(1689): 20150203.

Groot, C., and Cooke, K. 1987. Are the migrations of juvenile and adult Fraser River sockeye salmon (Oncorhynchus nerka) in near-shore waters related. In Sockeye Salmon (O. nerka) Population Biology and Future Management. Edited by H.D. Smith, L. Margolis and C.C. Wood. Canadian Special Publication of Fisheries and Aquatic Sciences. No 96. pp. 53-60. Groot, C., and Margolis, L. 1991. Pacific salmon life histories. UBC press, Vancouver, Canada. Grosholz, E.D. 1992. Interactions of intraspecific, interspecific, and apparent competition with host-pathogen population dynamics. Ecology, 73(2): 507-514.

Hamre, L.A., Eichner, C., Caipang, C.M.A., Dalvin, S.T., Bron, J.E., Nilsen, F., Boxshall, G., and Skern-Mauritzen, R. 2013. The salmon louse Lepeophtheirus salmonis (Copepoda: Caligidae) life cycle has only two chalimus stages. PloS one, 8(9): e73539.

Hargreaves, N.B., and LeBrasseur, R.J. 1986. Size selectivity of coho (Oncorhynchus kisutch) preying on juvenile chum salmon $(O$. keta). Canadian Journal of Fisheries and Aquatic Sciences, 43(3): 581-586. doi: 10.1139/f86-069. 
477

478

479

480

481

482

483

484

485

486

487

488

489

490

491

492

493

494

495

496

497

498

Hatcher, M.J., Dick, J.T., and Dunn, A.M. 2006. How parasites affect interactions between competitors and predators. Ecology Letters, 9(11): 1253-1271. doi: 10.1111/j.14610248.2006.00964.x

Houde, E., and Hoyt, R. 1987. Fish early life dynamics and recruitment variability. Transactions of the American Fisheries Society.

Hurvich, C.M., and Tsai, C.-L. 1989. Regression and time series model selection in small samples. Biometrika, 76(2): 297-307. doi: 10.1093/biomet/76.2.297.

Igboeli, O.O., Burka, J.F., and Fast, M.D. 2014. Lepeophtheirus salmonis: a persisting challenge for salmon aquaculture. Animal Frontiers, 4(1): 22-32. doi: 10.2527/af.2014-0004.

Jakob, E., Sweeten, T., Bennett, W., and Jones, S. 2013. Development of the salmon louse Lepeophtheirus salmonis and its effects on juvenile sockeye salmon Oncorhynchus nerka. Diseases of Aquatic Organisms, 106(3): 217-227. doi: 10.3354/dao02642.

Johnson, S., Blaylock, R., Elphick, J., and Hyatt, K. 1996. Disease induced by the sea louse (Lepeophtheirus salmonis)(Copepoda: Caligidae) in wild sockeye salmon (Oncorhynchus nerka) stocks of Alberni Inlet, British Columbia. Canadian Journal of Fisheries and Aquatic Sciences, 53(12): 2888-2897. doi: 10.1139/f96-226.

Johnson, S.C., Bravo, S., Nagasawa, K., Kabata, Z., Hwang, J., Ho, J., and Shih, C. 2004. A review of the impact of parasitic copepods on marine aquaculture. Zoological Studies, 43(2): 229-243.

Jones, S., Kim, E., and Bennett, W. 2008. Early development of resistance to the salmon louse, Lepeophtheirus salmonis (Krøyer), in juvenile pink salmon, Oncorhynchus gorbuscha (Walbaum). Journal of Fish Diseases, 31(8): 591-600. 
Kabata, Z. 1972. Developmental stages of Caligus clemensi (Copepoda: Caligidae). Journal of the Fisheries Research Board of Canada, 29(11): 1571-1593. doi: 10.1139/f72-245.

Krkošek, M., Morton, A., and Volpe, J.P. 2005a. Nonlethal assessment of juvenile pink and chum salmon for parasitic sea lice infections and fish health. Transactions of the American Fisheries Society, 134(3): 711-716. doi: 10.1577/t04-133.1.

Krkošek, M., Lewis, M.A., and Volpe, J.P. 2005b. Transmission dynamics of parasitic sea lice from farm to wild salmon. Proceedings of the Royal Society of London B: Biological Sciences, 272(1564): 689-696. doi: 10.1098/rspb.2004.3027.

Krkošek, M., Gottesfeld, A., Proctor, B., Rolston, D., Carr-Harris, C., and Lewis, M.A. 2007. Effects of host migration, diversity and aquaculture on sea lice threats to Pacific salmon populations. Proceedings of the Royal Society of London B: Biological Sciences, 274(1629): 3141-3149. doi: 10.1098/rspb.2007.1122.

Krkošek, M., Connors, B.M., Morton, A., Lewis, M.A., Dill, L.M., and Hilborn, R. 2011 la. Effects of parasites from salmon farms on productivity of wild salmon. Proceedings of the National Academy of Sciences, 108(35): 14700-14704.

Krkošek, M., Connors, B.M., Ford, H., Peacock, S., Mages, P., Ford, J.S., Morton, A., Volpe, J.P., Hilborn, R., Dill, L.M., and Lewis, M.A. 201 1b. Fish farms, parasites, and predators: implications for salmon population dynamics. Ecological Applications, 21(3): 897-914. doi: 10.1890/09-1861.1.

Landingham, J.H., Sturdevant, M.V., and Brodeur, R.D. 1998. Feeding habits of juvenile Pacific salmon in marine waters of southeastern Alaska and northern British Columbia. Fishery Bulletin, 96(2): 285-302. 
Lee, R.F. 1974. Lipids of zooplankton from Bute inlet, British Columbia. Journal of the Fisheries Board of Canada, 31(10): 1577-1582.

Mackas, D., Galbraith, M., Faust, D., Masson, D., Young, K., Shaw, W., Romaine, S., Trudel, M., Dower, J., and Campbell, R. 2013. Zooplankton time series from the Strait of Georgia: Results from year-round sampling at deep water locations, 1990-2010. Progress in Oceanography, 115: 129-159.

Mages, P.A., and Dill, L.M. 2010. The effect of sea lice (Lepeophtheirus salmonis) on juvenile pink salmon (Oncorhynchus gorbuscha) swimming endurance. Canadian Journal of Fisheries and Aquatic Sciences, 67(12): 2045-2051.

Maksimowich, D.S., and Mathis, A. 2000. Parasitized salamanders are inferior competitors for territories and food resources. Ethology, 106(4): 319-329.

Masson, D., and Peña, A. 2009. Chlorophyll distribution in a temperate estuary: The Strait of Georgia and Juan de Fuca Strait. Estuarine, Coastal and Shelf Science, 82(1): 19-28.

McKinnell, S., Curchitser, E., Groot, K., Kaeriyama, M., and Trudel, M. 2014. Oceanic and atmospheric extremes motivate a new hypothesis for variable marine survival of Fraser River sockeye salmon. Fisheries Oceanography, 23(4): 322-341. doi: 10.1111/fog. 12063. Milinski, M. 1984. Parasites determine a predator's optimal feeding strategy. Behavioral Ecology and Sociobiology, 15(1): 35-37.

Miller, K.M., Teffer, A., Tucker, S., Li, S., Schulze, A.D., Trudel, M., Juanes, F., Tabata, A., Kaukinen, K.H., and Ginther, N.G. 2014. Infectious disease, shifting climates, and opportunistic predators: cumulative factors potentially impacting wild salmon declines. Evolutionary Applications, 7(7): 812-855. 
Moore, J.W., Mooers, A.O., and Gallaugher, P. (2017). Speaking for the salmon. The protection of Pacific wild salmon: understanding potential risk factors and seeking solutions. Available from http://www.sfu.ca/content/dam/sfu/pwrc/PDFs/SfSJan2017Recommendations.pdf. Accessed 2017-04-26.

Morton, A., Routledge, R., and Krkošek, M. 2008. Sea louse infestation in wild juvenile salmon and Pacific herring associated with fish farms off the east-central coast of Vancouver Island, British Columbia. North American Journal of Fisheries Management, 28(2): 523-532. doi: 10.1577/M07-042.1.

Moss, J.H., Beauchamp, D.A., Cross, A.D., Myers, K.W., Farley, E.V., Murphy, J.M., and Helle, J.H. 2005. Evidence for size-selective mortality after the first summer of ocean growth by pink salmon. Transactions of the American Fisheries Society, 134(5): 1313-1322. doi: $10.1577 / \mathrm{t} 05-054.1$.

Mustafa, A., Rankaduwa, W., and Campbell, P. 2001. Estimating the cost of sea lice to salmon aquaculture in eastern Canada. The Canadian Veterinary Journal, 42(1): 54.

Nakagawa, S., and Schielzeth, H. 2013. A general and simple method for obtaining R $^{2}$ from generalized linear mixed-effects models. Methods in Ecology and Evolution, 4(2): 133-142. doi: 10.1111/j.2041-210x.2012.00261.x

Nendick, L., Sackville, M., Tang, S., Brauner, C., and Farrell, A. 2011. Sea lice infection of juvenile pink salmon (Oncorhynchus gorbuscha): effects on swimming performance and postexercise ion balance. Canadian Journal of Fisheries and Aquatic Sciences, 68(2): 241249. 
Pacific Salmon Commission. (2016). Fraser river panel weekly report - August 19, 2016. Available from http://www.psc.org/download/71/2016/4572/weeklyreport06.pdf. Accessed 2017-04-26.

Parker, R.R. 1968. Marine mortality schedules of pink salmon of the Bella Coola River, central British Columbia. Journal of the Fisheries Board of Canada, 25(4): 757-794.

Parsons, T., LeBrasseur, R., and Barraclough, W. 1970. Levels of production in the pelagic environment of the Strait of Georgia, British Columbia: a review. Journal of the Fisheries Board of Canada, 27(7): 1251-1264.

Peacock, S.J., Connors, B.M., Krkošek, M., Irvine, J.R., and Lewis, M.A. 2014. Can reduced predation offset negative effects of sea louse parasites on chum salmon? Proceedings of the Royal Society of London B: Biological Sciences, 281(1776): 20132913.

Peacock, S.J., Krkošek, M., Bateman, A.W., and Lewis, M.A. 2015. Parasitism and food web dynamics of juvenile Pacific salmon. Ecosphere, 6(12): 1-16.

Price, M.H.H., Proboszcz, S.L., Routledge, R.D., Gottesfeld, A.S., Orr, C., and Reynolds, J.D. 2011. Sea louse infection of juvenile sockeye salmon in relation to marine salmon farms on Canada's west coast. PLoS ONE, 6(2): e16851. doi: 10.1371/journal.pone.0016851.

Price, M.H.H., Glickman, B.W., and Reynolds, J.D. 2013. Prey selectivity of Fraser River sockeye salmon during early marine migration in British Columbia. Transactions of the American Fisheries Society, 142(4): 1126-1133. doi: 10.1080/00028487.2013.799517.

Resetarits, W.J. 1995. Limiting similarity and the intensity of competitive effects on the mottled sculpin, Cottus bairdi, in experimental stream communities. Oecologia, 104(1): 31-38. Saksida, S.M., Morrison, D., and Revie, C.W. 2010. The efficacy of emamectin benzoate against infestations of sea lice, Lepeophtheirus salmonis, on farmed Atlantic salmon, Salmo salar 
L., in British Columbia. Journal of Fish Diseases, 33(11): 913-917. doi: 10.1111/j.13652761.2010.01192.x.

Sapir, N., Butler, P.J., Hedenström, A., and Wikelski, M. 2011. Energy gain and use during animal migration. In Animal Migration. Edited by E. Milner-Gulland, J.M. Fryxell and A.R. Sinclair. Oxford University Press, New York. pp. 52-67.

Schall, J.J. 1992. Parasite-mediated competition in Anolis lizards. Oecologia, 92(1): 58-64.

Scharf, F.S., Juanes, F., and Rountree, R.A. 2000. Predator size-prey size relationships of marine fish predators: interspecific variation and effects of ontogeny and body size on trophic-niche breadth. Marine Ecology Progress Series, 208: 229-248.

Shi, Z.-h., Liu, S.-S., and Li, Y.-x. 2002. Cotesia plutellae parasitizing Plutella xylostella: hostage dependent parasitism and its effect on host development and food consumption. BioControl, 47(5): 499-511.

Sutherland, G., Foreman, M., and Garrett, C. 2007. Tidal current energy assessment for Johnstone Strait, Vancouver island. Proceedings of the Institution of Mechanical Engineers, Part A: Journal of Power and Energy, 221(2): 147-157.

Sutherland, W.J. 1996. From individual behaviour to population ecology. Oxford University Press, New York.

Tanasichuk, R., and Routledge, R. 2011. An investigation of the biological basis of return variability for sockeye salmon (Oncorhynchus nerka) from Great Central and Sproat lakes, Vancouver Island. Fisheries Oceanography, 20(6): 462-478.

Ward, A.J., Webster, M.M., and Hart, P.J. 2006. Intraspecific food competition in fishes. Fish and Fisheries, 7(4): 231-261. 
609 Welch, D.W., Melnychuk, M.C., Payne, J.C., Rechisky, E.L., Porter, A.D., Jackson, G.D., Ward, 610 B.R., Vincent, S.P., Wood, C.C., and Semmens, J. 2011. In situ measurement of coastal 611 ocean movements and survival of juvenile Pacific salmon. Proceedings of the National 612 Academy of Sciences, 108(21): 8708-8713.

613 Welker, M.T., PiERCE, C.L., and Wahl, D.H. 1994. Growth and survival of larval fishes: roles 614 of competition and zooplankton abundance. Transactions of the American Fisheries Society, 615 123(5): 703-717.

616

Wootten, R., Smith, J.W., and Needham, E. 1982. Aspects of the biology of the parasitic

617 copepods Lepeophtheirus salmonis and Caligus elongatus on farmed salmonids, and their

618

619 treatment. Proceedings of the Royal Society of Edinburgh. Section B: Biological Sciences, 81(03): 185-197. doi: 10.1017/s0269727000003389. 


\section{$621 \quad$ Tables}

622 Table 1. Infection categories and sample sizes for each fish collection. The infection scale was

623 weighted such that one large chalimus louse was equal to one infection unit, one motile louse

624 was equal to two infection units, and copepodite and small chalimus lice were equal to zero

625 units. For each collection, a single fish pair was comprised of one fish from the highly infected

626 category and one from the lightly infected category.

\begin{tabular}{|c|c|c|c|c|c|}
\hline \multirow[b]{2}{*}{ Collection } & \multirow[b]{2}{*}{ Fish pairs } & \multicolumn{2}{|c|}{ Lightly infected } & \multicolumn{2}{|c|}{ Highly infected } \\
\hline & & Infection scale & Max. lice & Infection scale & Min. lice \\
\hline 1 & 5 & 0 & 3 & 4 & 6 \\
\hline 2 & 6 & 0 & 1 & 3 & 2 \\
\hline 3 & 7 & 0 & 1 & 4 & 5 \\
\hline 4 & 7 & 0 & 2 & 4 & 4 \\
\hline 5 & 6 & 0 & 3 & 4 & 4 \\
\hline 6 & 7 & 0 & 3 & 4 & 7 \\
\hline 7 & 6 & 0 & 3 & 4 & 6 \\
\hline 8 & 5 & 0 & 3 & 5 & 7 \\
\hline 9 & 5 & 0 & 3 & 5 & 4 \\
\hline 10 & 6 & 0 & 3 & 5 & 9 \\
\hline 11 & 5 & 0 & 3 & 5 & 10 \\
\hline Average & 5.9 & 0.0 & 2.5 & 4.3 & 5.8 \\
\hline
\end{tabular}

627 
628 Table 2. Model selection results for the six models of relative foraging success that accounted for 629 at least $5 \%$ of model support. Relative stomach fullness was calculated as wet stomach content 630 weight divided by body weight. The models included combinations of infection category 631 (infection), body size (size; see description of principal component analysis), and prey density 632 fixed effects. Each model included a random effect on the intercept for collection number. 633 Interaction terms are distinguished with an asterisk symbol. See Supplementary Table S3 for the 634 full model set and selection results.

\begin{tabular}{clccc}
\hline Rank & \multicolumn{1}{c}{ Model } & $\Delta \mathrm{AICc}^{*}$ & $w_{i}^{\dagger}$ & $R^{2 \ddagger}$ \\
\hline 1 & infection & 0 & 0.358 & 0.549 \\
2 & infection + size & 1.24 & 0.192 & 0.530 \\
3 & infection + prey & 1.66 & 0.156 & 0.542 \\
4 & infection + size + prey & 2.66 & 0.095 & 0.510 \\
5 & infection*size & 3.85 & 0.052 & 0.530 \\
6 & infection*prey & 3.91 & 0.051 & 0.536 \\
\hline *
\end{tabular}

635 "Difference from the top model AICc $(\triangle \mathrm{AICc})$

$636+$ Akaike model weight $\left(w_{i}\right)$

$637 R^{2}$ for mixed-effects models calculated using the method developed by Nakagawa and 638 Schielzeth (2013) 


\section{$639 \quad$ Figures}

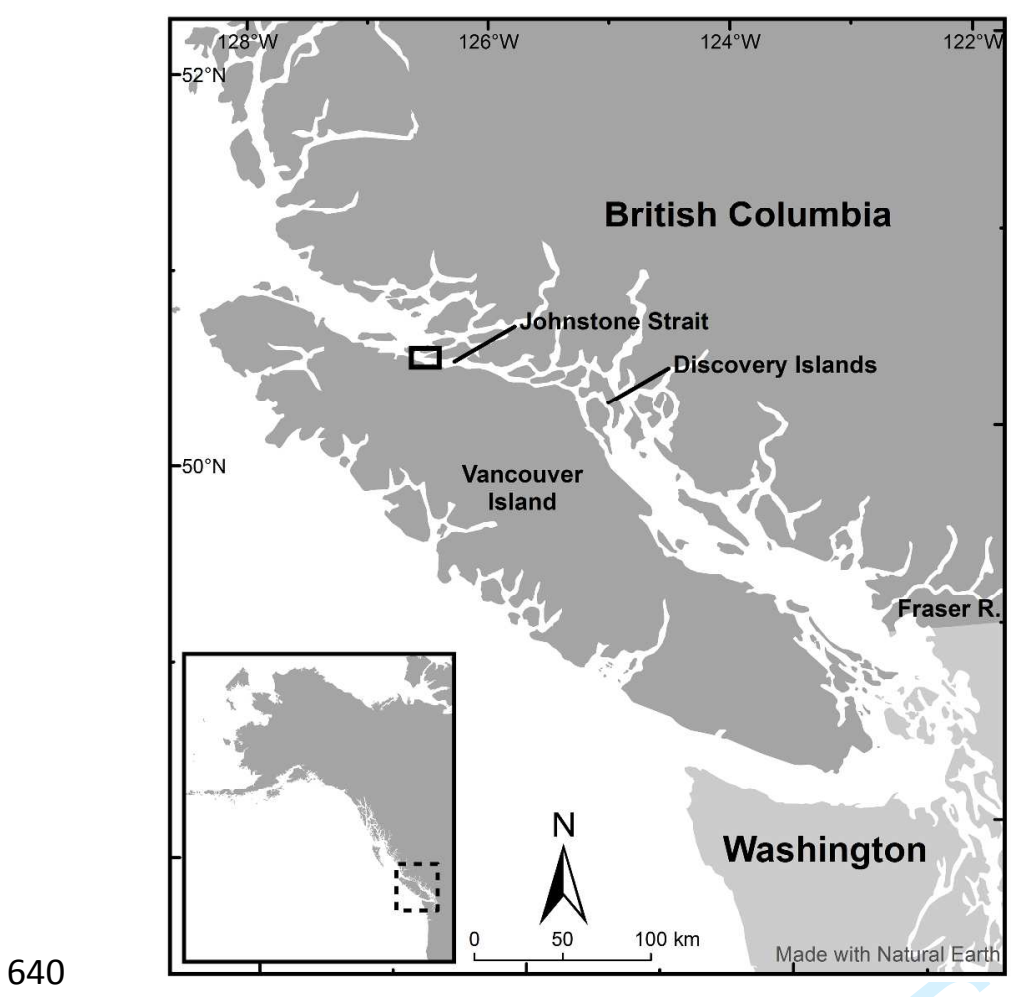

641 Fig. 1. Map of study region. The solid black box indicates the area in which salmon collections 642 occurred. 


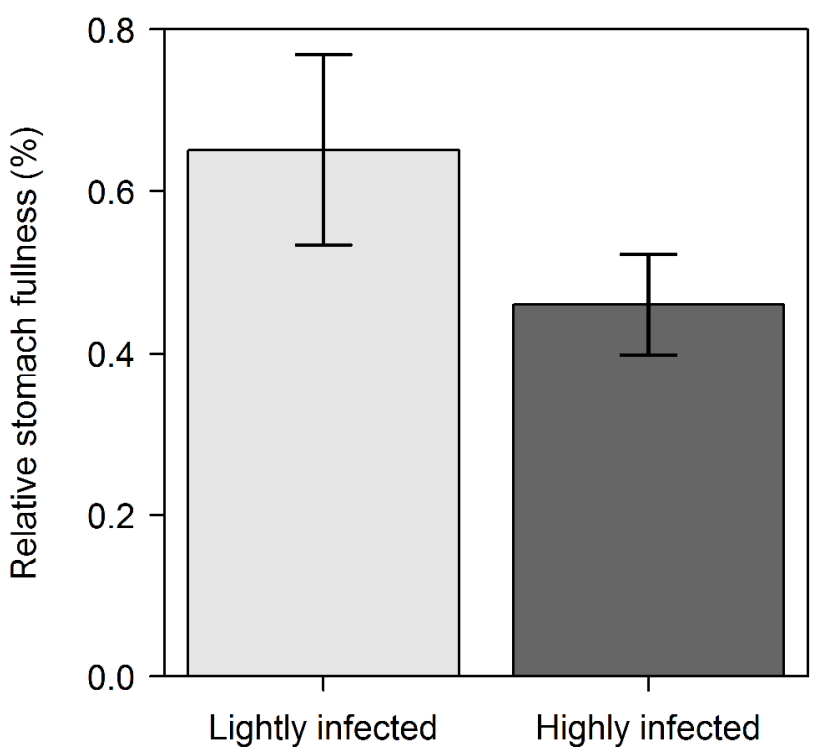

643

644 Fig. 2. Relative stomach fullness of juvenile sockeye salmon for the two categories of sea louse 645 infection. Error bars indicate the 95\% confidence intervals around the relative stomach fullness 646 for each infection category. 


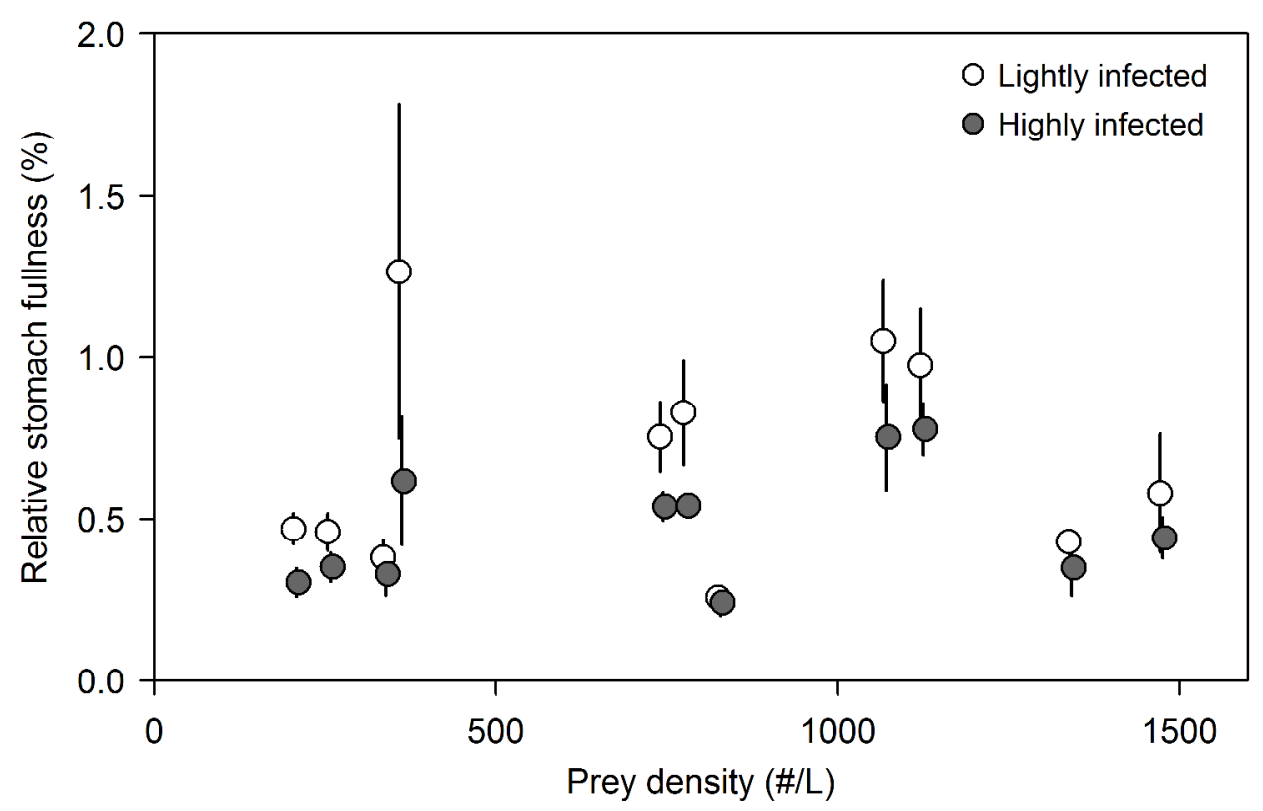

Fig. 3. Mean relative stomach fullness $( \pm \mathrm{SE})$ for fish in both infection categories of each

649 collection. Each vertical pair of points (one grey, one white) comprises a single collection. The 650 relationship between relative stomach fullness and prey density had equivocal support in our 651 model selection results (see Table S3). 


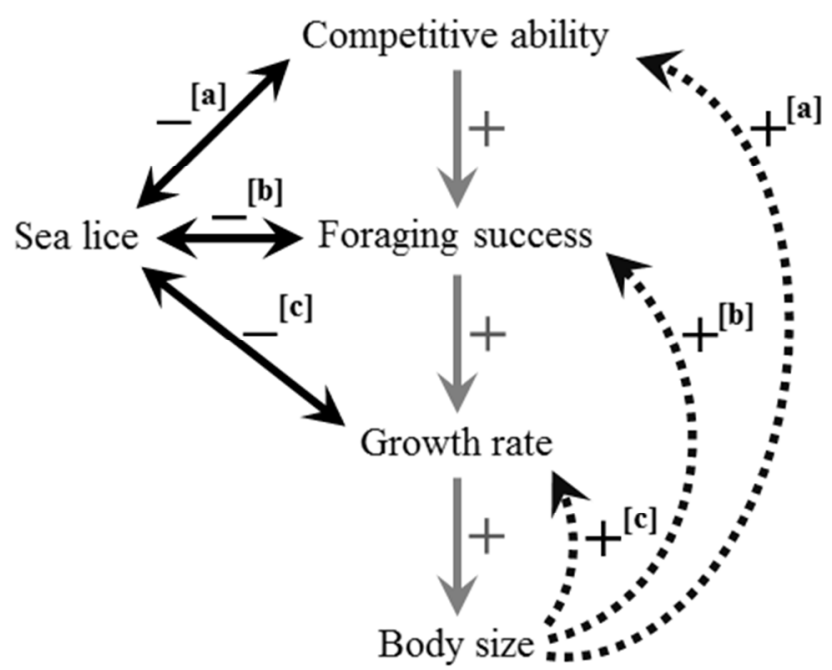

652

653 Fig. 4. Relationships among juvenile sockeye salmon traits and sea louse infection. Solid double654 ended arrows indicate established correlative sea louse relationships ([a] Godwin et al. 2015, [b] 655 this paper, [c] Godwin et al. 2017). Dashed black arrows indicate established correlative body 656 size relationships, and grey arrows indicate implicit mechanistic relationships. 
Appendix. Juvenile sockeye salmon digestion experiment

2

3

4

5

6

\section{Methods}

To assess the extent to which our prey density estimates were representative of the prey field met by the juvenile sockeye salmon (O. nerka) when they had been feeding, we needed to determine how quickly juvenile sockeye digested their prey. To accomplish this, we performed a small feeding experiment at a floating field facility comprised of several floating docks and net pens. We collected fish at the same Johnstone Strait location used in the main study and transported them by boat for $1 \mathrm{~h}$ to the experimental facility (see Fig. 1 in Godwin et al. (2015) for map). During transport, the sockeye were again held in insulated fish totes with bubblers and ice packs. We did not collect temperature or salinity data for this experiment, but previous studies using the same experimental facility and juvenile salmon collection sites have indicated that their water temperatures and salinities are very similar (Atkinson et al. In review; Godwin et al. 2015).

Upon arrival at the facility, we transferred the fish to a large $(2.8 \mathrm{~m}$ deep and $6.1 \times 6.1 \mathrm{~m}$ across) net pen and weaned them onto frozen brine shrimp (Brine Shrimp Direct, Ogden, Utah, USA) over the next five days. Brine shrimp were thawed in freshwater and were fed to the fish by adding them to the center of the net pen. Medium-sized fish (between 107 and $120 \mathrm{~mm}$ ) were removed for another study, leaving 31 smaller $(104.1 \mathrm{~mm} \pm 0.4 \mathrm{~mm})$ and 37 larger $(124.9 \pm 0.7$ $\mathrm{mm}$ ) fish. The fork length range of these experimental fish was $97 \mathrm{~mm}$ to $132 \mathrm{~mm}$, which was fully within the fork length range of the fish from the main study ( $88 \mathrm{~mm}$ to $133 \mathrm{~mm}$ ).

One hour after sunrise on their sixth day at the experiment facility, the 68 fish were fed to satiation and ten were immediately sacrificed with a lethal dose of MS-222. At half, one, two, 
24 three, five hours after initial feeding, ten fish were again randomly removed and euthanized, 25 leaving remaining fish. At eight hours, these eight fish were removed and euthanized. We 26 weighed the wet stomach contents of the fish in the same manner as for those sacrificed in the

27 field, and calculated relative stomach fullness by dividing the weight of each fish by the weight 28 of its wet stomach contents.

29 We fit a Michaelis-Menten curve to the relative stomach fullness data and used these 30 parameter estimates to calculate the amount of digestion that occurred between time points in the 31 experiment.

32

33 Results

34 The digestion rate of the experimental fish began high and gradually slowed over time 35 (Fig. A1). Six fish did not consume any brine shrimp and were therefore removed from the 36 dataset. After one hour, $37 \%$ of the initial stomach contents remained, and after the final hour of 37 the experiment (hour eight) only $18 \%$ remained. The predicted relative stomach fullness of the 38 experimental fish at hour eight $(0.6 \%)$ was similar to the mean relative stomach fullness of the 39 main study's fish (0.6\%), suggesting that most of the main study's fish must have eaten in the 40 previous eight hours since not all of them would have fed to satiation like the experimental fish. 


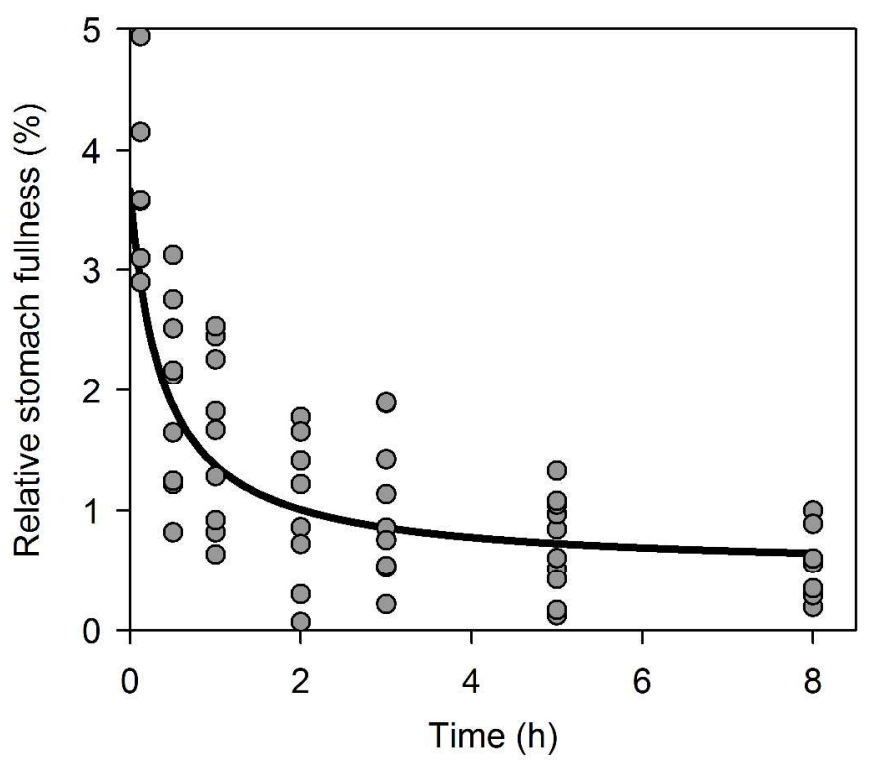

41

42 Fig. A1. Relative stomach fullness of juvenile sockeye salmon over the course of the digestion

43 rate experiment, with a Michaelis-Menten curve fit to the data (black line). Six fish were

44 removed from this dataset because they did not consume any food.
46

47

48

49

50

51

52

\section{References}

Atkinson, E., Bateman, A.W., Dill, L.M., Krkošek, M., Reynolds, J.D., and Godwin, S.C. In review. Oust the louse: leaping behaviour removes sea lice from wild juvenile sockeye salmon.

Godwin, S.C., Dill, L.M., Reynolds, J.D., and Krkošek, M. 2015. Sea lice, sockeye salmon, and foraging competition: lousy fish are lousy competitors. Canadian Journal of Fisheries and Aquatic Sciences, 72(7): 1113-1120. doi: 10.1139/cjfas-2014-0284. 